\title{
Modeling, Simulation, and Implementation of a Solar Thermoelectric Energy Harvesting System
}

\author{
Yacouba Moumouni and R. Jacob Baker \\ Department of Electrical and Computer Engineering, University of Nevada, Las Vegas, NV 89119, USA
}

Received: March 17, 2016 / Accepted: March 24, 2016 / Published: May 31, 2016.

\begin{abstract}
New alternatives and inventive renewable energy techniques which encompass both generation and power management solutions are fundamental for meeting remote residential energy supply and demand today, especially if the grid is quasi-inexistent. Solar thermoelectric generators mounted on a dual-axis sun tracker can be a cost-effective alternative to photovoltaics for remote residential household power generation. A complete solar thermoelectric energy harvesting system is presented in this paper for energy delivery to remote residential areas in developing regions. To this end, the entire system was built, modeled, and then validated with the LTspice simulator software via the thermal-to-electrical analogy schemes. Valuable data in conjunction with a novel LTspice circuit were obtained, showing the achievability of analyzing transient heat transfer with the SPICE simulator; however a few of the problems to be solved remain at the practical level. Despite the unusual operation of the thermoelectric modules with the solar radiation, the simulation and measurements were in good agreement, thus validating the new modeling strategy.
\end{abstract}

Key words: Solar thermoelectric generator, developing regions, LTspice, DC-DC converter, thermal-to-electrical analogy.

\section{Introduction}

Energy is vital to the extent that it completes and sustains billions of luxurious lives today. Without energy, cold and hunger would leave many people vulnerable to all sorts of diseases. Fossil fuels are indisputably the major source of energy across the world- $80 \%-85 \%$ - whereby the most common are oil, coal and natural gas. Energy emanating from fossil fuel is somewhat less expensive to produce. In addition, most of the technology today is designed toward the utilization of residual fuels. Nevertheless, the latter are non-regenerative energy sources at a human scale, and they are destined to be depleted in the future. In fact, the global tendency is that, the Earth is running out of energy resources that are either non-renewable at all or not replenishing at a faster rate. Some of the

Corresponding author: Yacouba Moumouni, research scientist, research fields: renewable energy applications, concentrated PV integration onto the grid with buffers, energy storage system analysis and applications, PV off-grid applications, and thermoelectric generator systems modeling and applications. alternative sources, such as wind, hydropower, and geothermal produce not only some pollutants along their process, but also destroy the environment.

Hence, solar energy is one of the most abundant and cleanest renewable sources in the universe, because it is free from any GHG (greenhouse gas) and other harmful environmental pollutants. It also requires no incursion upon the natural wild animals' habitats if harnessed with environmentally-friendly semiconductor devices, such as PV (photovoltaic) and TEG (thermoelectric generator). In fact, solar energy's immensity, year round availability, and benign effect on the climate, have made it the most appealing energy source on Earth. In spite of the versatility and abundance of solar energy, very little of it is directly utilized to power human activities. If solar energy were to become a concrete alternative to fossil fuels, efficient ways to convert photons into electricity and useful heat must be engineered [1]. However, problems with solar renewable energy include variability due to weather events and the nocturnal 
absence [2]. Since solar energy is most of the time stochastic in nature, there is a great need for energy storage. As a result, it is noteworthy to point out that, energy storage can be utilized to mitigate renewable system transients [3].

Primarily, TEGs were exclusively assigned for space applications. Soon after that, they were applied, as stated throughout the literature, to many waste heat recoveries. Among these applications, TEGs have been proposed for woodstoves [4]; body heat powered watches [5]; car seat cooling/heating for passenger comfort by the major car manufacturers, including, but not limited to, Toyota, GM, Nissan, Ford and Range Rover [6]; bio-sensors [7]; industrial waste heat recovery to power ancillary devices [8]; vehicular waste heat recovery to enhance fuel economy [9]; and harvesting micropower for low power applications, such as wireless and mobile sensors [10]; just to mention a few. It should be pointed out that currently, TEG applications step beyond the above mentioned areas. Hence, STEG (solar thermoelectric generators) are irrefutably one of the most recent applications as reported by Crabtree, et al. [1], whereby the energy from the Sun is concentrated on the TEG in order to generate electrical power by means of the Seebeck theory.

Despite the advantages of thermal electric devices being solid, reliable heat energy converters, silent during the course of their operation, and lacking of any mechanical moving parts [11], their low energy conversion efficiency (5\%) has limited their applications to specialized situations as stated above [12]. It is worthy of note that, TEG is such a versatile technique capable of harnessing heat from naturally occurring sources of energy: for example, solar, geothermal, ocean thermal, and waste heat from micro to macro devices [13]. However, their potential of power generation by utilizing all sorts of heat, ranging from solar radiation to manmade heat sources, along with their maintenance free operation, caused TEGs to become technically attractive [14]. In contrast to PV systems, TEGs do not rely on solar radiation only. They are reliable and scalable quantities required in a green technology, applicable in harsh and arid environments, such as the Southwest of the US (United States), the Sahel in Africa, etc.

Previous studies mentioned rural electrification and domestic applications of TEG technology for lighting, heating, ventilating, etc. [15]. However, not many of these studies have looked into the thermal-to-electrical analogy which utilizes the LTspice simulator to analyze the transient heat transfer as we suggest in this study.

Yet, the study done by Chen, et al. [16] sought to find a SPICE model which was able to accurately describe how much time a TEG needs to stabilize after load change occurs. Their study had the drawback of idealizing $T_{h}$ and $T_{c}$ to be constant, whereas in reality, the Seebeck coefficient is dependent on temperature as demonstrated in Ref. [17]. Lineykin, et al. [18] aimed to develop a SPICE compatible equivalent circuit of a TEM (thermoelectric module). This study shows that, the modeling of the TEC (thermoelectric cooler) and the TEG was about the same. Consequently, the same circuit can be utilized to simulate both behaviors, providing the current direction is reversed. In addition, the TEG parameters were simply extracted from the datasheet. Unfortunately, there was a major drawback in that approach. There was not enough precision in the results because, not only the thermal resistance of the aluminum plates was assumed to be negligibly small, but also the thermal capacitance of the isolation chamber was neglected. These assumptions surely affected the accuracy of the overall results.

However, an improved micro energy harvesting TEG was implemented in a SPICE simulator [19]. As compared to the study just mentioned above, the current one accounted for variations of the internal electrical resistance $\left(R_{I n t}\right)$ of the Peltier module's dependence on temperature. The study's results show that $R_{\text {int }}$ was dependent on temperature; it also affected 
the performance of TEG. Nevertheless, a better accuracy was achieved in the range of small temperature gradients.

As a final review, Mihail Cernaianu [20] and Gontean, et al. [21] proposed an energy harvesting system by means of the LTspice simulator. Their improved model was solely based on the thermal-to-electrical modeling schemes. They investigated the variation of the parameters, such as Seebeck coefficient, internal resistance and thermal conductance, as heat was being transferred from the hot to the cold side of the TEG. Furthermore, a DC-DC converter (LTC 3105) was used to boost the TEG's output voltage to a desired level needed to charge the battery. In both studies, the authors did use current-dependent sources rather than voltage-dependent sources because they claimed that, the former was proved to solve different convergence problems that may appear in simulations due to the large number of variables. The drawback of these energy harvesting systems was that, they were limited to laboratory experiment. Therefore, they did not have as significant an impact as if they were conducted in a real-world environment to harvest the free and abundant solar energy.

The proposed model is based on the internal parameter fluctuations, such as Seebeck coefficient, parasitic inductance $(L)$ and capacitance $(C)$, and the internal resistance of the TEG. In addition, the proposed system is a real-world environment solar energy harvester mounted on a dual-axis tracker. It is important to specify that, the values of the parasitic $C$, and $L$ were borrowed from a previous work reported in Ref. [22] because they cannot be determined with the equipment available to us.

This paper is organized as follows. Section II describes the DC solar thermoelectric generation system. In Section III, the important parameter calculations are presented. Section IV emphasizes on the STEG model implementation in LTspice via the thermal-to-electrical analogy. The major results and their implications are discussed in Section V, followed by a brief conclusion in Section VI.

\section{DC STEG System Description}

The design of a solar thermoelectric generation system from scratch has never been free from challenges in terms of transient heat transfer analysis, and the amount of heat to be converted to electrical power. One of the key challenges worth mentioning in solar thermoelectric power conversion is how to achieve a significant differential temperature across the TEG devices using the local DNI (direct normal insolation) only. The STEG system would likely utilize the IR (infrared) portion, which is about $42 \%$ of the solar spectrum, to achieve the $\Delta T$ needed to supply power to the remote regions. Hence, the temperature drop across the devices would have been, under certain specific condition, in the range of $1-5{ }^{\circ} \mathrm{C}$ [23], exclusively based on the conventional heat conduction, whereby:

$$
\Delta T=\frac{q L}{\kappa}
$$

where, $q$ is the heat flux traversing the TEG, $L$ is its length, $\kappa$ is the thermal conductivity, and $\Delta T$ is $T_{H}$ (hot side temperature) minus $T_{C}$ (cold side temperature).

Obviously, the above temperature drop would have been too small for efficient power generation to happen. In order to differ from the conventional wisdom in terms of TEG, which stipulated that, TEMs were only suitable for waste heat recovery, the aim of this paper is two-fold: (1) demonstrate TEGs remain an attractive renewable technology that can convert solely the solar irradiance into electrical energy for energy delivery to remote residential areas; and (2) STEG's transient heat transfer analysis through thermal-to-electrical analogy by means of the LTspice simulator in comparison to the traditional analytical methods can not only be achieved, but can also greatly simplify the task at hand by improving the system's overall understanding. So, the electrical power generated by the STEG devices is given by Eq. (2). 


$$
P_{\text {Elect }}=Q_{h}-Q_{C}=\alpha \cdot \Delta T \cdot I+R_{\text {Int }} \cdot I^{2}=I^{2} \cdot R_{L}
$$

where, $Q_{h}, Q_{C}, R_{I n t}, \alpha, \kappa$ and $I$ represent, respectively: the total heat transferred from the hot side due to Seebeck effect, thermal conductance, and Joule heating; the total heat flow at the cold side also due to Seebeck effect, thermal conductance, and Joule heating; the internal resistance of the TEM; the Seebeck coefficient; the thermal conductivity; and the electrical current through the STEG system.

As it is customary in electrical power engineering, maximum transfer occurs when a load resistance $\left(R_{L}\right)$ matches the internal resistance $\left(R_{I n t}\right)$ of a generation system, in this case the STEG. This equality is represented by Eq. (3).

$$
I=\alpha \cdot \frac{\Delta T}{2 R}
$$

However, to achieve the desired goals, this study opted for tracking the Sun in a consistent manner, although such an initiative may incur an extra cost to the system. This idea may be viewed as a non-attractive investment, given the small overall thermoelectric generator's efficiency stated throughout the literature.

\subsection{Research Methodology}

This work proposes to design, build and test a solar thermoelectric generation system. The schematic overview of the investigated solar TEG energy harvesting system is presented in Fig. 1. Possible methods to enhance its efficiency, understand its functionality, and optimize its performance, i.e., the heat transfer capabilities between the top and the bottom surfaces, were investigated. The thermal to the electrical analogy scheme was adopted to simulate the designed energy harvesting model by means of the LTspice simulator software. Experimental and simulated results were collected and then succinctly analyzed.

This study ought to achieve the following objectives. First is to investigate the performance of commercial solar TEGs under arid weather conditions comparable to the Southwest of the US or the Sahel in Africa. The TEG devices made of bismuth telluride $\left(\mathrm{Bi}_{2} \mathrm{Te}_{3}\right)$ were chosen to be five in number and were mounted on a dual-axis solar tracker. The heat absorbing side of the TEGs was exposed to four reflectors covered with a highly reflective thin film material. These reflectors attached to the tracker, were positioned in such a way that, the sun was concentrated four times on the devices. In addition, on top of the emitting side of the TEGs was sitting an aluminum (Al) HEX (heat exchanger), which created the requisite differential temperature between the two sides. In order to prevent

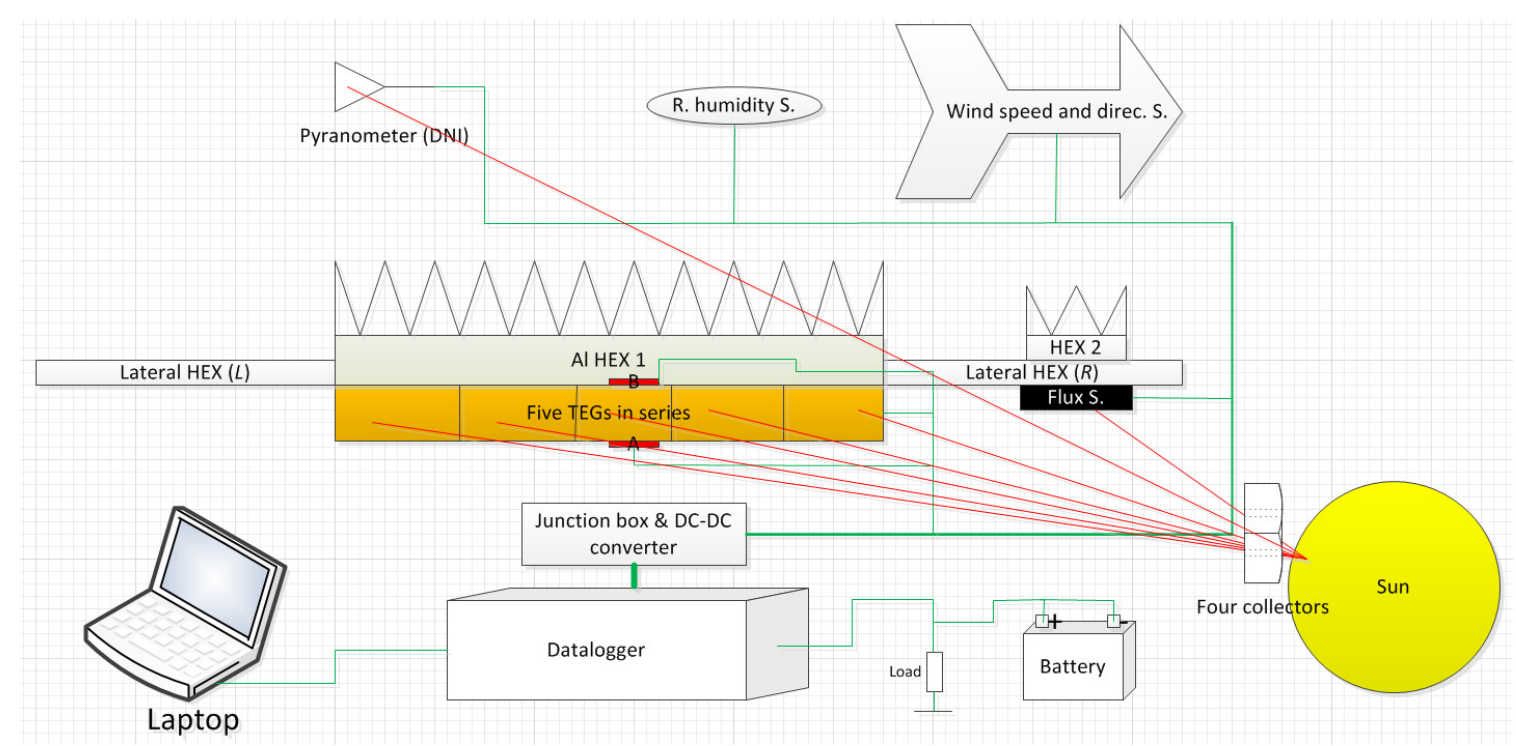

Fig. 1 STEG schematic overview-A and B denote thermocouples. 


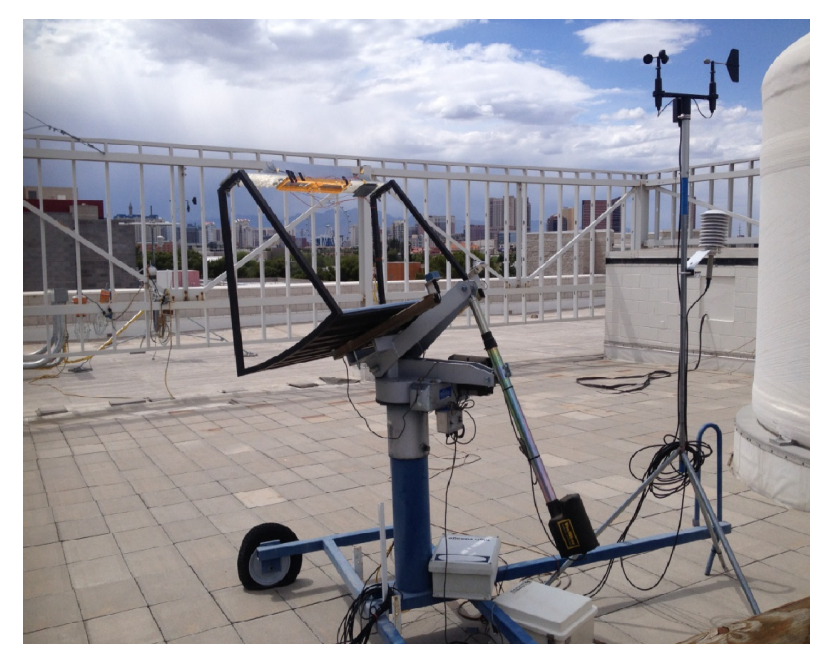

Fig. 2 Solar thermoelectric generation system.

the four suns to shine directly on the HEX, polyurethane insulation foam was glued around the set of TEGs as can be seen in Fig. 2. Also, two lateral aluminum flat plates of equal dimensions were utilized as part of the components to build this solar energy harvesting system. Their primary purpose was to extend the aluminum HEX in order to be able to fasten it to the main iron structure. The secondary purpose of the Al plates, which was as important as the first one, was to enable them to actively participate in the overall heat removal away from the colder side of the TEGs. In other words, they extended the functionality of the main HEX. In addition to that, the base of the HEX was grooved to form a meandering channel with an oval shape to accommodate a $\mathrm{K}$ type thermocouple (A), which was placed on the back of one of the TEGs to measure $T_{C}$. Also, a second $\mathrm{K}$ type thermocouple (B) was placed on the polyurethane foam, in the middle of the two sets of TEGs, via the same technique to record $T_{H}$.

The second part of the research was to not only compute the electrical parameters from both device geometries and properties, but also, and most importantly, to accomplish the electrical analogy of the whole system with the SPICE simulator. The basic idea of the present model was derived from previous works done by Refs. [17, 24-26]. So far, this study is the only one attempting to model a real-world environment STEG energy harvesting system utilizing LTspice. The temperature dependence of the internal resistance was taking into account in the model via the arbitrary behavioral voltage source technique. Also, a lookup table of real experimental data (the local DNI, meaning the hot side temp.) was fed into the circuit to: (1) simulate the real behavior and (2) improve simulation speed. Moreover, all the heat capacitance values calculated in Section III were scaled down in the SPICE model in order to significantly reduce the running time created by the magnitude of the electrical equivalent circuit. The LTspice's built-in PWL (piecewise linear) command was purposely utilized in order to achieve the anticipated goals set forward.

Hence, due to the complexity in the geometry and unique nature of the STEG system in addition to the corresponding projected longer simulation time, some assumptions were essential. The thermal capacitance of the dynamical volume of air between the four collectors and the five TEGs was assumed to be equivalent to the specific heat capacity of dry air at $80^{\circ} \mathrm{C}$. In a like manner, the thermal resistance of that same unquantifiable amount of air was assumed to be its thermal conductivity, $\kappa=0.0299 \mathrm{~W} /(\mathrm{m} \cdot \mathrm{K})$ for simplicity in the approach. The thermal resistance of the heat transfer grease was assumed to be $0.45 \mathrm{~K} \cdot \mathrm{W}$ [24]. Then, both the experimental and simulated data recorded were analyzed and compared in Sec. V.

Ultimately, all the thermal components, such as $L$, $C$ and $R$ determined in Section III or assumed for technical limitations, were strategically connected either in series and/or in parallel to reconstruct the electronic model of the entire STEG system in LTspice. As a decisive step, the STEG is ready to be modeled in SPICE provided the relevant codes were written down properly.

Finally, due to the stochastic nature of solar energy most of the time, there is a potential need for energy storage as stated in Section I. Hence, the amount of energy harvested will be stored in rechargeable batteries for a later usage. 


\subsection{Brief Description of the Major Components}

As reported in Refs. [27, 28], the complexity of any engineering system comes not from the multitude number of parts, but rather from the inner complexity of each single unit. Having that concept in mind, in designing an STEG, there are many more complexities that must be meticulously considered. In essence, each single unit must be assessed thoroughly and separately, and then evaluated in conjunction with the rest of the system as a whole. Figs. 1 and 2 illustrate the equivalent schematic overview of the system and the actual STEG setup, respectively. Commercial TEGs, 2411G-7L31-15CX1, made by custom thermoelectric with a size of 56 by 56 millimeters were tested for energy delivery to remote residential areas in developing regions. The five TEGs were all connected electrically in series and thermally in parallel. Above the cold side of the TEGs was a customized aluminum HEX, which not only removes the heat, but also provides an adequate differential temperature across them. Along the focal point of the tracker was a solar flux sensor. It was intended to measure the magnitude of the four suns, obviously different from the DNI recorded by the pyranometer. The secondary HEX was utilized to cool the flux sensor down. The rest of the components mounted on a separate iron structure built for the purpose are-relative humidity sensor, wind speed and direction sensors - as can be seen on the right hand side of Fig. 2. The output of the TEGs, the two thermocouples, and the pyranometer in conjunction with all the sensors, were all connected to a data logger. A laptop was utilized in order to collect the experimental data once a week. The knowledge of the DNI, relative humidity, the wind speed and its direction, tell us how the local weather affects the instant, average, and total power generated by the energy harvesting system.

\section{Parameter Extraction}

A total of five TEGs were used in the proposed energy harvesting system. The heat capacity and the internal thermal resistance of each module were estimated in the previous work to be $23 \mathrm{~J} / \mathrm{K}$ and $0.64 \mathrm{~K} / \mathrm{W}$, respectively [29]. The former value was further split into two equal parts to fit in the LTspice model, as that yielded to accurate STEG modeling and the best possible solutions.

The modules were specified by the manufacturer to be bismuth telluride $\left(\mathrm{Bi}_{2} \mathrm{Te}_{3}\right)$ and that the ceramic substrates were made of alumina $\left(\mathrm{Al}_{2} \mathrm{O}_{3}\right)$. So by virtue of that, some of the properties that turned out to be useful in the succeeding computations were densities, specific heat capacities, and the thermal conductivities of the $\mathrm{Al}$ HEXs, the substrate, and the $\mathrm{Bi}_{2} \mathrm{Te}_{3}$, as mentioned in Ref. [29]. Table 1 lists the most relevant values.

Table 1 TEG properties.

\begin{tabular}{llll}
\hline Material & $\rho\left(\mathrm{kg} / \mathrm{m}^{3}\right)$ & $c(\mathrm{~J} /(\mathrm{kg} \cdot \mathrm{K}))$ & $\kappa(\mathrm{W} /(\mathrm{m} \cdot \mathrm{K}))$ \\
\hline Aluminum & 277 & 875 & 177 \\
Alumina & 3,570 & 837 & 35.3 \\
$\mathrm{Bi}_{2} \mathrm{Te}_{3}$ & 7,530 & 544 & 1.5 \\
\hline
\end{tabular}

where, $\rho$ is density, $c$ is specific heat, and $\kappa$ is conductivity.

Two heat exchangers were used in this design: (1) the main heat sink was placed on the cold side of the TEGs in order to keep them as cool as possible; (2) the secondary heat sink was utilized to remove the heat from the bifacial solar flux sensor. Stated clearly, the role of each one of those heat exchangers is independent from one another and they are of the extruded type, made of pure aluminum material. Therefore, only the former HEX will be given further consideration in this study as it played a core role in the design. Besides, in computing the thermal resistance and capacitance of the following parts, the geometries and properties were solely taking into account.

\subsection{Aluminum Heat Exchanger}

The dimensions of the primary heat exchanger were carefully documented, and then listed in Table 2. In addition to that, the lateral aluminum plates were also measured. These plates also contributed to remove 
some of the heat from the TEGs, since they were fastened directly beneath the main heat exchanger and adjacent to the insulation foam. The overall SPICE simulation of the thermal process would not be accurate without properly taking into consideration the aforementioned plates.

\subsubsection{Thermal Resistance, $R_{H E X}$}

Besides the dimensions listed in Table 2, it is worthy of note to point out that, the heat exchanger is of pure aluminum. The total number of fins is eight and the distant between them is about $0.635 \mathrm{~cm}$. So, the area, $A_{H E X}$, of the heat exchanger can be simply calculated by Eq. (4).

$A_{\text {HEX }}=l \cdot W=0.50165 \times 0.0762=0.0383 \mathrm{~m}^{2}$

where, $l$ is the length of the Al heat exchanger in meters (m) and $W$ is its width, also in meters.

With the perfectly documented knowledge of all the physical dimensions of the Al HEX's contact area, the associated thermal resistance can be found by Eq. (5).

$$
R_{H E X}=\frac{1}{\kappa \cdot(A / l)}=0.074 \mathrm{~K} / \mathrm{W}
$$

where, $\kappa=177 \mathrm{~W} / \mathrm{m}$ is the thermal conductivity, $A$ is the surface area, and $l$ is the length of the $\mathrm{Al}$ heat exchanger.

\subsubsection{Thermal Capacitance, $C_{H E X}$}

In a similar fashion, the volume of the plate-fin HEX needs to be computed although it is much more cumbersome and involving as compared ordinary aluminum plates. The HEX has eight (8) fins, whereby the first seven (7) fins are of the same dimensions, but the eighth one, i.e., Fin $_{B}$, has an odd size as displayed in Table 3.

Where, all the units were measured in millimeters (mm).

For simplicity purposes, we assumed the thicknesses at the bottom and the top of the two categories of fins to be the same size and then utilized their average $\left(t_{\text {avg }}\right)$ in our calculations. Therefore, determining their volume is solely reduced to calculating the volume of a rectangular parallelepiped as can be seen in Eq. (6).

$$
V_{\text {Fin_A }}=l \cdot h \cdot t_{\text {avg }}=0.00009361 \mathrm{~m}^{3}
$$

where, $l, h$ and $t_{\text {avg }}$ are the length, the height and the average thickness, respectively.

The volume of the seven fins, $V_{\text {Total }}$, of equal size can be calculated as follows, Eq. (7).

$$
V_{\text {Total }}=7 \cdot V_{\text {Fin_A }}=0.00066 \mathrm{~m}^{3}
$$

Following a similar judgment, the volume of the unique $\mathrm{Fin}_{B}$, can be determined after averaging its bottom and top thicknesses as in Eq. (8).

$$
V_{\text {Fin_B }}=l \cdot h \cdot t_{\text {avg }}=0.00007489 \mathrm{~m}^{3}
$$

The volume of the two categories of fins can be summed up to the overall volume, $V_{\text {Fins }}$, by:

$$
V_{\text {Fins }}=V_{\text {Total }}+V_{\text {FinB }}=0.000735 \mathrm{~m}^{3}
$$

Table 2 Dimensions of the physical components.

\begin{tabular}{llllll}
\hline No & Components & Length $(\mathrm{cm})$ & Height $(\mathrm{cm})$ & Width $(\mathrm{cm})$ & Thickness $(\mathrm{cm})$ \\
\hline 1 & Heat exchanger 1 & 50.165 & 7.112 & 7.62 & 0.985 \\
2 & Lateral Al plate $(R)$ & 30.48 & 0.635 & 10.16 & 10.16 \\
3 & Lateral Al plate $(L)$ & 30.48 & 0.635 & $31.115(W)$ & \\
4 & PUR insulation foam & $40.132(l)$ & $1.905(h)$ & $5.715\left(W_{1}\right)$ & \\
5 & Insulation foam (hole 1) & $16.764\left(l_{1}\right)$ & 1.905 & $5.715\left(W_{2}\right)$ & \\
6 & Insulation foam (hole 2) & $16.764\left(l_{2}\right)$ & 1.905 & 5.6 & \\
7 & TEG & 5.6 & 0.445 & & \\
\hline
\end{tabular}

Table 3 Fins' dimensions.

\begin{tabular}{llllll}
\hline Designation & Quantity & Length $(l)$ & Height $(h)$ & Thickness $\left(t_{a}\right)$ & Thickness $\left(t_{b}\right)$ \\
\hline Fin $_{A}$ & 7 & 501.65 & 62.20 & 3.60 & 2.40 \\
Fin $_{B}$ & 1 & 501.65 & 62.20 & 2.70 & 2.10 \\
\hline
\end{tabular}


The Al HEX's compact base volume computation, where all the fins originated, is now made straightforward, knowing the length, the width and the height as can be seen by Eq. (10).

$$
V_{\text {Base }}=l \cdot w \cdot h=0.00037652 \mathrm{~m}^{3}
$$

Finally, the volume of the entire HEX, $V_{H E X}$, as written in Eq. (11), can be assessed by summing up the individual volumes calculated above.

$$
V_{H E X}=V_{\text {Base }}+V_{\text {Fins }}=0.00111152 \mathrm{~m}^{3}
$$

Hence, the heat capacity proper, $C_{H E X}$, needed to accurately model the heat exchanger's effect on the STEG system, via the SPICE simulator, can be computed by Eq. (12).

$$
C_{H E X}=\rho \cdot C p \cdot V_{H E X}=2,694 \mathrm{~J} / \mathrm{K}
$$

where, $\rho$ is the density, $C_{p}$ is the specific heat capacity and $V_{H E X}$ is the volume of the Al HEX.

\subsection{Lateral Aluminum Plates}

Two aluminum plates of equal dimensions were utilized as part of the components to build this solar energy harvesting system. Their primary purpose was to extend the aluminum HEX in order to be able to fasten it to the main iron structure. The secondary purpose of the Al plates, which is as important as the first one, is that they actively participate in removing the heat away from the colder side of the TEGs.

\subsubsection{Thermal Resistance, $R_{L A l}$}

As already mentioned, the physical dimensions are all summarized in Table 2. Consequently, the thermal resistances of the twin $\mathrm{Al}$ plates can simply be evaluated by Eq. (13).

$$
R_{L A l}=\frac{1}{\kappa \cdot(A / l)}=0.056 \mathrm{~K} / \mathrm{W}
$$

where, $\kappa=177 \mathrm{~W} / \mathrm{m}$ is the thermal conductivity, $A$ is the surface area of the plate, and $l$ is its length.

It is therefore worth noting that, the actual thermal resistance of the twin Al plates, $R_{\text {LAl_Total, }}$, be twice as much as $R_{L A l}$ shown in Eq. (14).

$$
R_{\text {LAl_Total }}=2 \cdot R_{L A l}=0.112 \mathrm{~K} / \mathrm{W}
$$

3.2.2 Thermal Capacity, $C_{L A l}$

Having measured with ultimate care the length $(l)$, width $(w)$, and height $(h)$ of the two lateral Al plates as listed in Table 2, it is now of a paramount importance to compute the total volume, $V_{\text {LAl_Total }}$, using Eq. (15), as it is needed in the subsequent equation.

$$
\begin{gathered}
V_{L A l_{\text {Total }}}=V_{L A l_{R}}+V_{L A l_{L}}=2 \cdot l \cdot w \cdot h \\
=0.0004 \mathrm{~m}^{3}
\end{gathered}
$$

where, $V_{L A l_{-} R}$ and $V_{L A l_{L} L}$ denote the volumes of the right and left lateral Al plates, respectively.

So, the heat capacity of the two lateral Al HEXs, $C_{L A l}$, needed to accurately model the whole new concept of the energy harvesting system with the SPICE software is determined by Eq. (16). It would then be converted into an equivalent electrical value by means of the thermal-to-electrical analogy theory and then fit in the circuit in order to simulate its real impact on the performance of the STEG.

$$
C_{L A l}=\rho \cdot C p \cdot V_{L A l_{\text {Total }}} \approx 970 \mathrm{~J} / \mathrm{K}
$$

where, $\rho$ is the density of the lateral Al plates and $C_{p}$ is their specific heat capacity.

\subsection{Thermal Insulation Foam}

To study the effects of insulation materials in this design, a rigid PUR (polyurethane foam) was specially selected to best fit the needs. It is important to mention here that, the rigid PUR is quite different from the common insulation foams as it is a closed-cell plastic. Also, PUR has an immensely great resistance to thermal energy propagation since it is one of the most efficient, high performance insulation materials, enabling a very effective way of preventing the solar radiation to directly shine on the HEX mounted on the cold side of the TEGs.

Thermal insulation, in most cases, is needed either to keep a device cool or warm, depending on the application. The thermal conductivity and the heat capacity of the insulation foam were first tested in a laboratory up to temperatures greater than $100{ }^{\circ} \mathrm{C}$.

Heat transfers naturally through a polyurethane foam by conduction in a form of atomic vibration (phonon) as well as radiation in some extent. Further, the particular phonons of interest in this study are the 
shorter-wavelength ones of higher frequency because they give rise to heat.

\subsubsection{Thermal Resistance, $R_{\text {Insul }}$}

One of the most important properties of any insulation material is inarguably its insulation performance. The benchmark for such insulation performance is a high thermal resistance or a low thermal conductivity. Further, it is worthy of note to emphasize that, the thermal resistance of any PUR is dependent on certain parameters, such as the cell gas used, density, temperature, behavior in the presence of water and moisture, and the time of measurement [30]. Hence, the most commonly utilized properties of this rigid PUR are enumerated in Table 4.

As can be seen from Fig. 3, computing the area and volume of the insulation foam can be somewhat involving because of the nature of its shape. So, the area of the insulation foam, $A_{\text {Insul }}$, can be obtained by Eq. (17).

$$
\begin{gathered}
A_{\text {Insul }}=l \cdot W-\left(l_{1} \cdot W_{1}+l_{2} \cdot W_{2}\right)=l \cdot W- \\
2 \cdot\left(l_{1} \cdot W_{1}\right)=0.106 \mathrm{~m}^{2}
\end{gathered}
$$

where, $l$ is the length of the insulation foam, $W$ is its width, $l_{1}$ is the inside length of the hole on the foam's surface located at the right, $W_{1}$ is the inside width of the hole on the foam's surface located at the right, $l_{2}$ is the inside length of the hole on the foam's surface located at the left, and $W_{2}$ is the inside width of the hole on the foam's surface located at the left.

The above equation is further reduced because, based on the measured values tabulated in Table 2 , the two rectangular holes cut into the surface of the foam were of equal dimensions. Hence, the mathematical expression for that is shown in Eq. (18) since $l_{1}$ is the same as $l_{2}$ and $W_{1}$ is identical to $W_{2}$.

$$
l_{1} \cdot W_{1}+l_{2} \cdot W_{2}=2 \cdot\left(l_{1} \cdot W_{1}\right)
$$

\section{Table 4 Rigid PUR properties.}

\begin{tabular}{llll}
\hline Material & $\begin{array}{l}\text { Thermal } \\
\text { conductivity, } \kappa\end{array}$ & Density, $\rho$ & $\begin{array}{l}\text { Specific heat } \\
\text { capacity, } C_{p}\end{array}$ \\
\hline $\begin{array}{l}\text { Rigid } \\
\text { polyurethane } \\
\text { foam, PUR }\end{array}$ & $0.025 \mathrm{~W} /(\mathrm{m} \cdot \mathrm{K})$ & $30 \mathrm{~kg} / \mathrm{m}^{3}$ & $1,500 \mathrm{~J} /(\mathrm{kg} \cdot \mathrm{K})$ \\
\hline
\end{tabular}

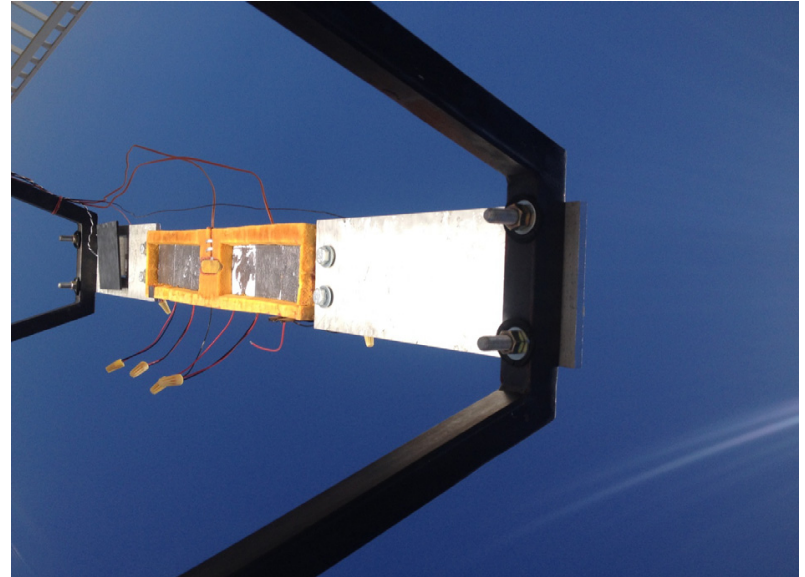

Fig. 3 Insulation foam facing the solar collectors.

Now that the area is known, the thermal resistance of the PUR, $R_{\text {Insul }}$, can be simply computed by means of Eq. (19).

$$
R_{\text {Insul }}=\frac{1}{\kappa \cdot(A / l)} \cong 109 \mathrm{~K} / \mathrm{W}
$$

where, $\kappa=0.025 \mathrm{~W} /(\mathrm{m} \cdot \mathrm{K})$ is the thermal conductivity, $A$ is the surface area, and $l$ is the approximate length of the insulation foam.

\subsubsection{Thermal Capacitance, $C_{\text {Insul }}$}

If we had not accommodated for the thermal insulation foam to fit in the design, the four suns would directly shine on the aluminum heat exchanger. The major consequence would then be purely a bad engineering design. The foam played a crucial role as it was the thermal barrier that kept the hot (front) side and the cold (back) side of the TEGs at different temperatures. Hence, placing the foam around and in the middle of the two groups of TEGs helped, not only to achieve a significant differential temperature, but also allowed the implementation of the Seebeck theory in a real-world experiment.

Information on the volume of the insulation foam, $V_{\text {Insul }}$, can be easily obtained from the previous knowledge of its area. Therefore, the volume is computed as in Eq. (20).

$$
V_{\text {Insul }}=A_{\text {Insul }} \cdot h=0.00202 \mathrm{~m}^{3}
$$

where, $h$ is the height of the insulation foam.

Finally, the heat capacity of the insulation foam can be numerically estimated, Eq. (21). 


$$
C_{\text {Insul }}=\rho \cdot C p \cdot V_{\text {Insul }}=91 \mathrm{~J} / \mathrm{K}
$$

where, $\rho$ is the density and $C_{p}$ is the specific heat capacity of the insulation foam.

\section{STEG Implementation in LTspice}

\subsection{Thermal-to-Electrical Analogy}

Most of the electrical and electronic engineers have a limited knowledge when it comes to analyzing the real behavior of transient heat in a semiconductor device, since the concept of heat transfer through any medium is entirely exclusive to their curriculum. So, modeling a TEM system with LTspice would have been confusing, had it not been clearly explained methodically step by step in preceding work. Therefore, the steps it takes to simulate any thermo-electrical system with the electronic LTspice simulator is wittingly over-looked in the current paper as the topic was already treated in detail [29]. In contrast, it has never been enough to illustrate, by means of Table 5, the most commonly used thermal-to-electrical analogies, as presented in Ref. [31].

\subsection{LTspice Implementation}

As it can be seen in Figs. 4 and 5, the complementary circuits of the SPICE model for the whole STEG system, are comprised of an electrical portion and a thermal circuit, in that order. The most important benefit of utilizing the LTspice simulator to model a complex transient heat transfer process is the convenience in viewing and interpreting the interactions between the four major effects: Seebeck, Joule, Peltier and Thomson.

With a sound knowledge of the energy equilibrium on both emitting and absorbing sides of the TEGs, the electrical power harvested can be simply quantified as done in Section II. There are mainly two alternative methods to model the energy balance and electrical power equations, as reported throughout the literature, viz., current dependent and voltage dependent sources. The former method was chosen for rapid convergence purposes. In contrast to some previous works, this
Table 5 Thermal-to-electrical equivalence.

\begin{tabular}{ll}
\hline Thermal & Electrical \\
\hline${ }^{\circ} \mathrm{C} /$ Watt & Ohm (resistor) \\
Joules $/{ }^{\circ} \mathrm{C}$ & Farad (capacitor) \\
Watt & Ampere (current source) \\
${ }^{\circ} \mathrm{C}$ & Volt (voltage source) \\
Ambient temperature & Ground $(0 \mathrm{~V})$ \\
\hline
\end{tabular}

study did incorporate the Seebeck coefficient, the thermal conductivity, and the internal thermal resistance variation with temperatures in the LTspice model through the ABVS (arbitrary behavioral voltage sources). Also, all the thermal resistances and capacities of the various physical parts of the STEG's system determined in Section III, were expressed in their electrical equivalence before reconstructing the energy harvesting system in SPICE. Hence, as can be seen in Figs. 4 and 5, all the parts obtained via the thermal-to-electrical analogies were either connected in series, and/or in parallel, to achieve the proposed STEG model. In addition to that, some of these components were equally split so that their effect would be perceived on either side of the STEG.

\subsubsection{Electrical Portion of the Circuit}

Fig. 4 depicts the electrical portion of the proposed STEG system, where the positive terminal at the end of the fifth TEG denotes the output voltage of the energy harvesting system. The communication between the thermal and electrical circuits was made possible by the voltage sources $V_{2}, V_{4}, V_{5}, V_{7}$ and $V_{9}$ through the current-voltage dependent schemes. It is extremely important to point out that, the internal parasitic components $\left(L_{n}\right.$ and $\left.C_{n}\right)$ were experimentally determined in Ref. [22], where the values are $0.54 \mu \mathrm{H}$ and $41 \mathrm{nF}$, respectively. In this particular electrical model, the pairs $\left(L_{n}, C_{n}\right)$ are respectively from $\mathrm{TEG}_{1}$ through TEG $\mathrm{TE}_{5}\left(L_{1}, C_{21}\right),\left(L_{2}, C_{20}\right),\left(L_{4}, C_{23}\right),\left(L_{6}, C_{25}\right)$, and $\left(L_{5}, C_{24}\right)$.

\subsubsection{Thermal Portion of the Circuit}

The proposed thermal model of our STEG system for solar energy harvesting is based on the initial works [21, 32]. Fig. 5 portrays the LTspice model of the thermal part of the proposed STEG energy 


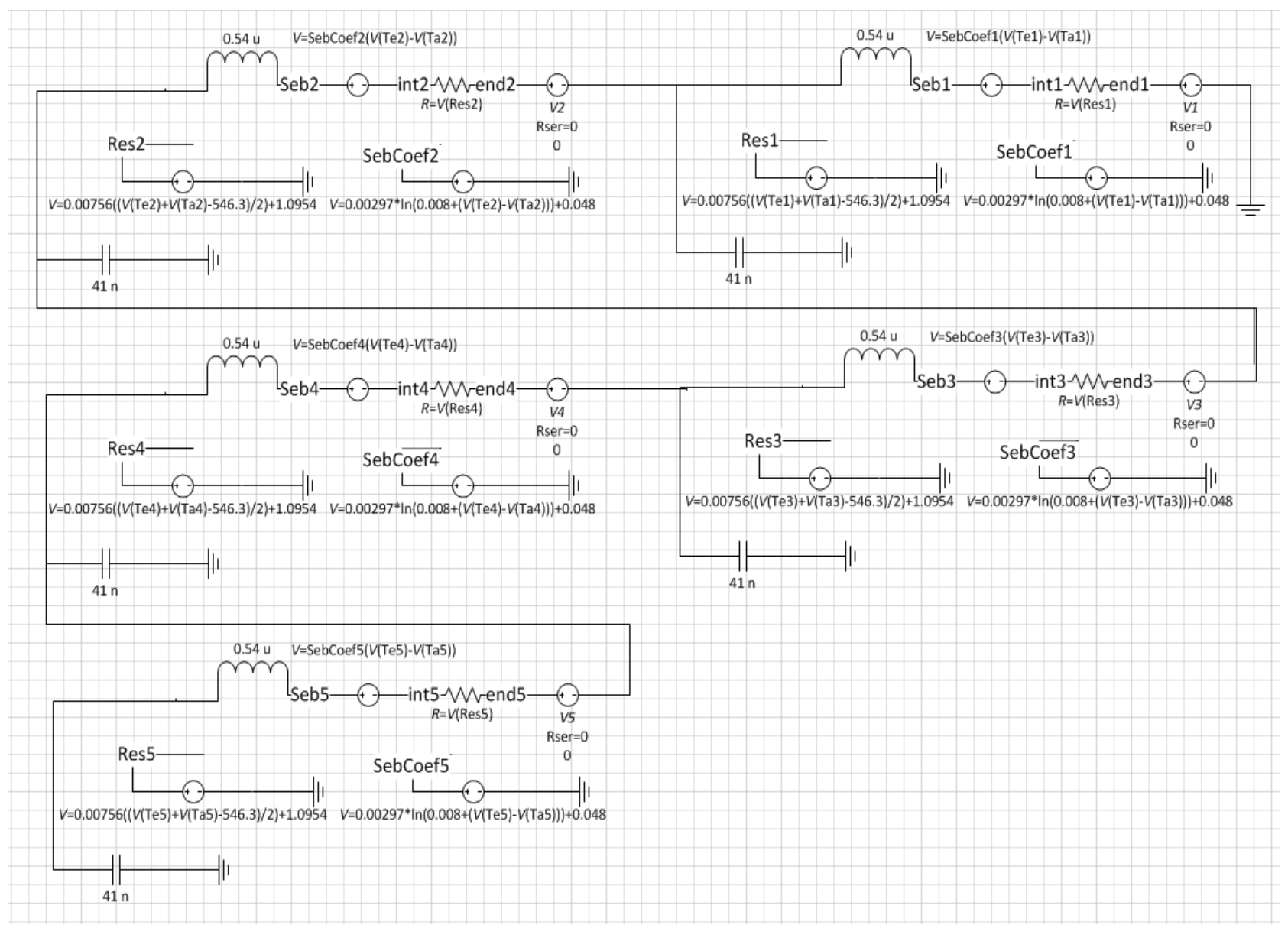

Fig. 4 Electrical portion of our STEG system, based on previous work.

harvesting system, where the five TEGs are connected electrically in series and thermally in parallel. In line with the same above reasoning, the following pairs of capacitances- $C_{1} \& C_{3}, C_{2} \& C_{4}, C_{22} \& C_{26}, C_{27} \&$ $C_{28}$, and $C_{29} \& C_{30}$-allowed us to capture the real-world performance of the STEG in LTspice. $R_{\text {Insul }}$ and $C_{\text {Insul }}$ represent the thermal resistance and thermal capacity of the polyurethane foam, respectively. In a like manner, the pairs $\left(R_{23} \& C_{14}\right)$ and $\left(R_{24} \& C_{15}\right)$ stand for the thermal resistance and thermal capacity of the two lateral aluminum plates, in that order.

\section{Results and Analysis}

\subsection{The Local Direct Solar Irradiance, DNI}

Fig. 6 portrays the local DNI experimentally recorded with a pyranometer mounted on a dual axis tracker. Each single unit represents the solar irradiance recorded during the course of a day. As it can be seen clearly, each day shows a unique insolation pattern with the effect of variability in it, relative to the local weather conditions. Hence, this variability as can be seen from Figs. 6-9, impacts tremendously and proportionally on the outcome of our experiment, viz. $\Delta T$ and energy harvested.

\subsection{Temperature Variation}

Fig. 7 shows the typical temperature profiles recorded, as well as simulated, for the two sides of the STEG system. These temperatures were plotted separately for clarity purposes. Otherwise, it would be hard to decipher if they were to be plotted altogether in the same graph. Figs. $7 \mathrm{a}$ and $7 \mathrm{c}$ on one hand, refer to the experimental and simulated temperatures across the 


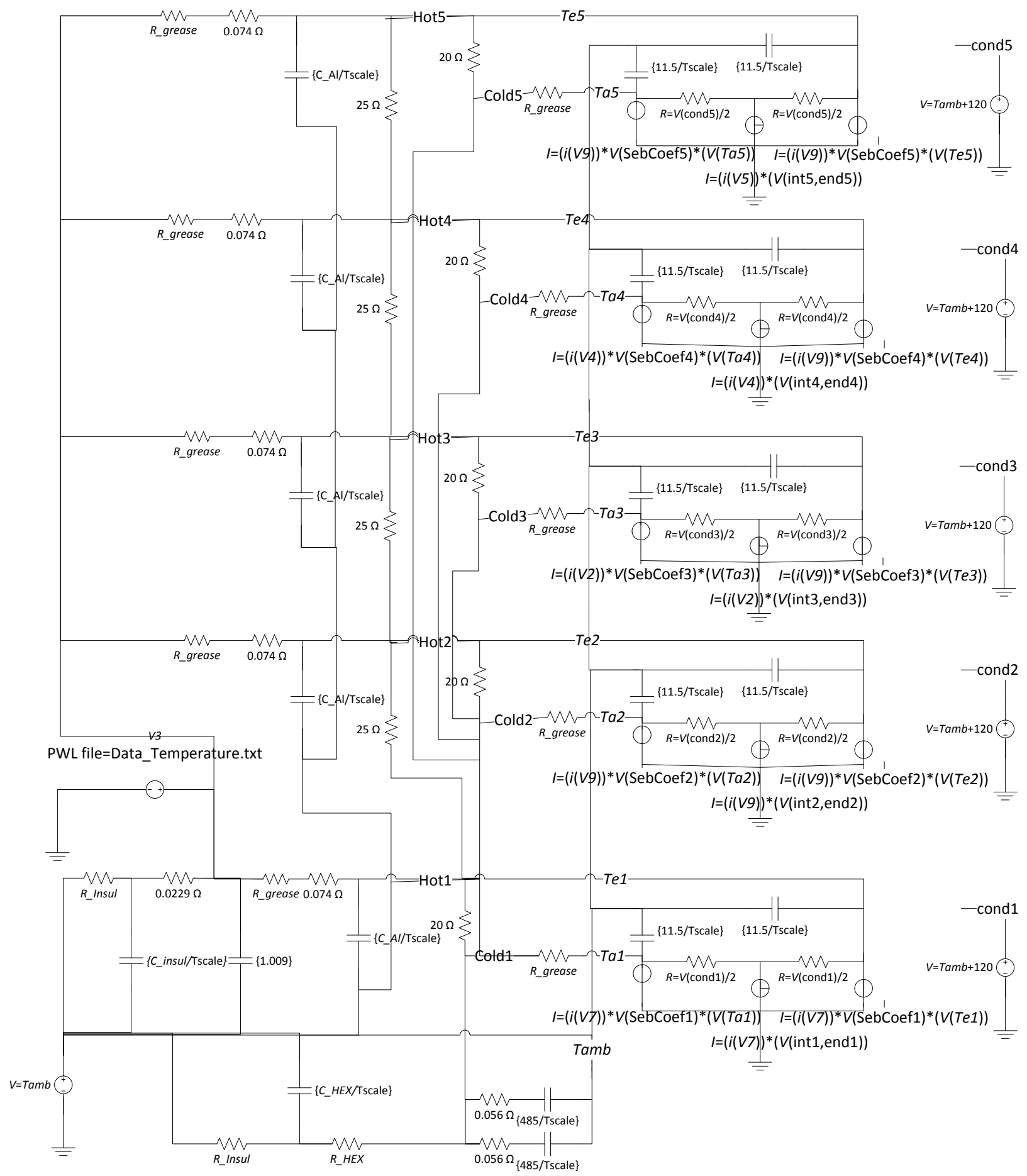

Fig. 5 Proposed thermal model of the STEG system.

energy harvesting system respectively, where $T_{H}$ is the same as $V\left(T e_{5}\right)$ and $T_{C}$ is meant by $V\left(T a_{5}\right)$. On the other hand, Figs. $7 \mathrm{~b}$ and $7 \mathrm{~d}$ illustrate the useful differential temperatures needed to produce a meaningful output voltage through the Seebeck effect.
As can be seen from these two curves $\left(\Delta T_{s}\right)$, the error rate between simulation and experiment varied from $0{ }^{\circ} \mathrm{C}$ to about $10{ }^{\circ} \mathrm{C}$, and more than $80 \%$ of it was attributable to the cold side of the STEG system. This acceptable discrepancy between the real-world solar 


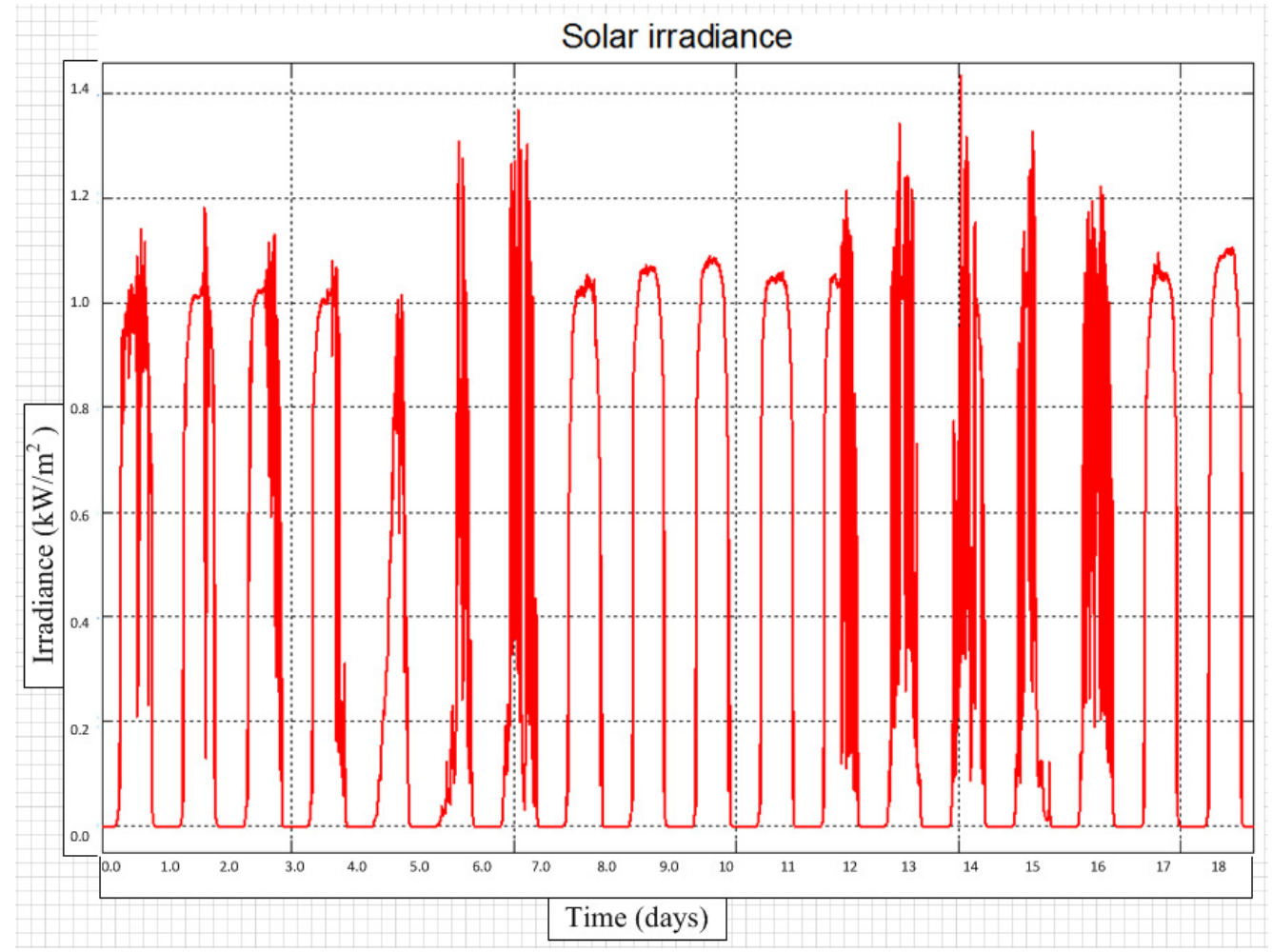

Fig. 6 Actual DNI recorded at site.

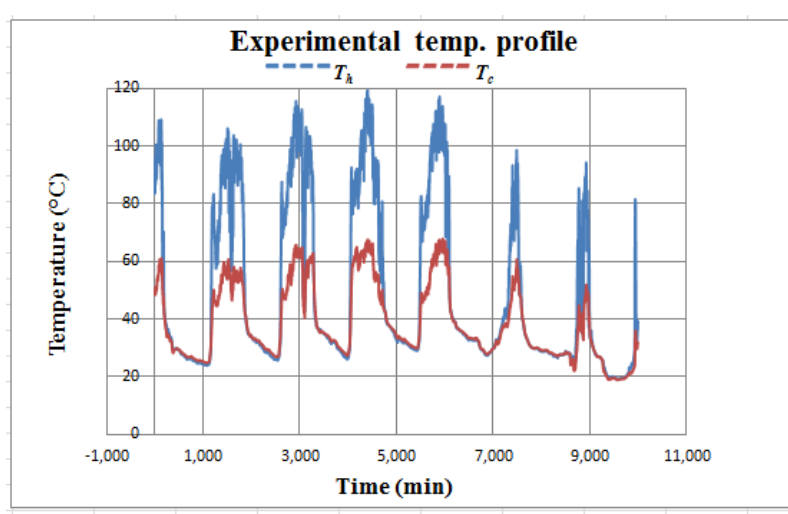

(a)

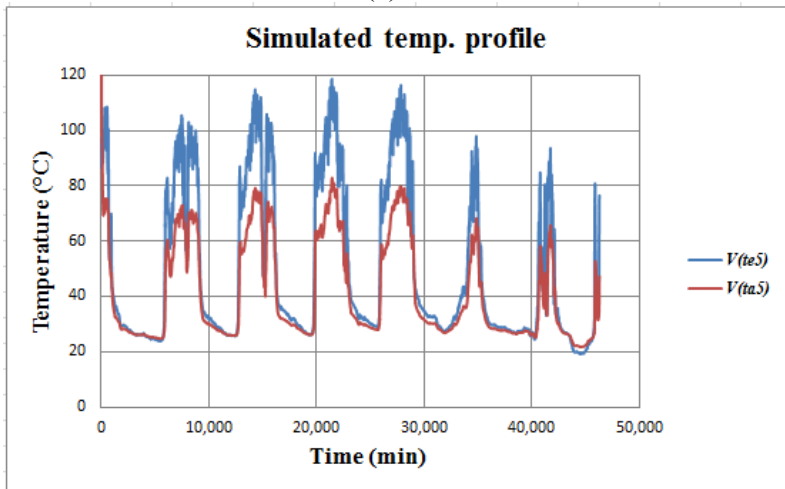

(c)

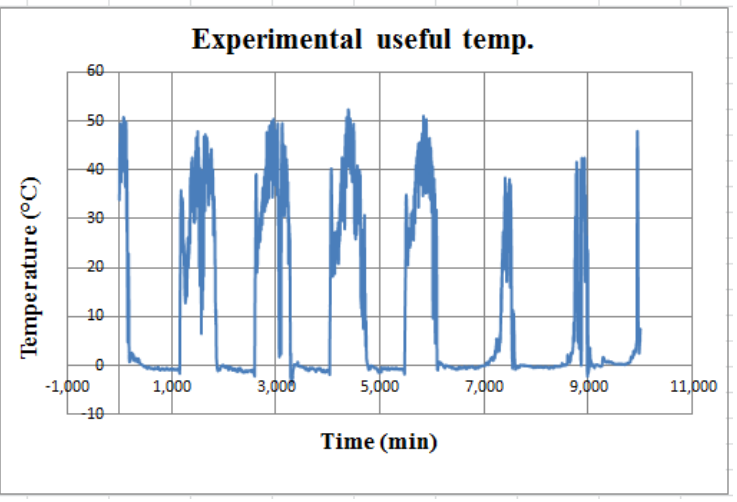

(b)

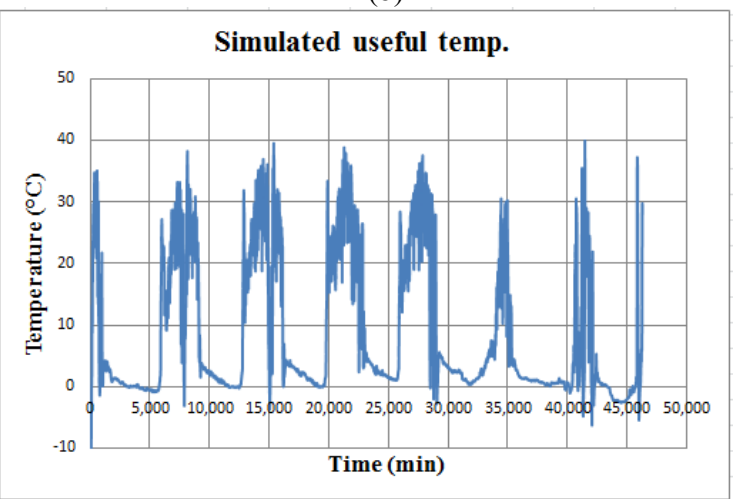

(d)

Fig. 7 Temperature variations across the STEG system: (a) experimental temperature profiles, (b) experimental $\Delta T$, (c) simulated temperature profiles, (d) simulated LTspice $\Delta T$. 
experiment and the LTspice model can be explained by either or both of the followings: (1) the internal parasitic components' variation and (2) the non-homogeneity of the aluminum blocks that were assumed to be pure metal heat exchangers during the computation of the thermal parameters. Another way of viewing this error is that, the LTspice model is roughly $25 \%$ less accurate than the actual experiment. The latter lesson would enable the rectification of any future similar design.

Additionally, two main findings can be identified. (1) The $\Delta T$, as significant as $50{ }^{\circ} \mathrm{C}$ was in both cases noticed to be proportional to the local DNI, which was the only input to the system. (2) Because of the law of proportionality stated above, the variability in the incoming sun light was likewise noticeable on the two sides' temperature of the STEG as seen in Figs. 7a and $7 c$.

\subsection{The Output Voltage}

This solar TEG energy harvesting system was designed and built to serve typical remote residential areas in developing regions. The local direct solar radiation, which was the only input to both experimental and the simulated systems, was recorded by means of a pyranometer. In other terms, the projected energy harvested for the benefit of the remote inhabitants, took into consideration not only the actual solar data at the site, but also took into consideration the typical weather conditions, such as relative humidity, rainfall, and wind speed and direction.

In a like manner, the issues of variability remain a critical factor even on the final output of the entire STEG system. As depicted in Fig. 8, the continuous voltage supplied, based on the above $\Delta T_{s}$ developed across the devices, varies between $0 \mathrm{~V}$ (case of complete cloud coverage or after sunset) to $8.57 \mathrm{~V}$ (clear summer sky) throughout the sample of days simulated. Hence, it is worthy to note that, since there are more sensible electronic gadgets in the rural households today, due to the breakthrough in cellular communication and the medical field, a DC-DC converter is solely recommended for a better lifespan of those appliances.

\subsection{Output Voltage Comparison}

As real local DNI data from our experiment were imported into the SPICE model via the built-in PWL commend, any intermittency in the insolation would automatically be reflected on the outcome of the model. Hence, as can be seen from Fig. 9, it is clear that, variability remains a big challenge even on the STEG energy harvesting system, when the outputs of two consecutive, but dissimilar days are compared. The energy harvested on a typical cloudy day is depicted on the left hand side, as compared to the graph on the right of the next day, which is a fairly normal day. It is important to note that, the unit does not always output the exact amount of power that it expected, because of severe weather events. Hence, this proves that variability due to cloud coverage affects STEG systems, the same way it affects PV systems. During cloudy weather conditions, the STEG's output changes suddenly by responding instantaneously to fluctuations in sunlight. An indirect consequence of this finding is that, in case a large STEG farm is tied to the grid, the system could have large and frequent ramp events that may create challenges for grid operators. Also, cloud coverage and STEG output variability are intimately related and could be dependent on the system size, shape, speed and other unknown natural factors. The average and root mean square values of the voltages generated by the system on these two consecutive days are: cloudy day-927.05 $\mathrm{mV}$ and $4.632 \mathrm{~V}$; normal day-2.2065 V and $5.0727 \mathrm{~V}$, respectively.

\section{Conclusions}

A standalone real-world environment solar thermoelectric generator energy harvesting system was designed, built and simulated for energy delivery 


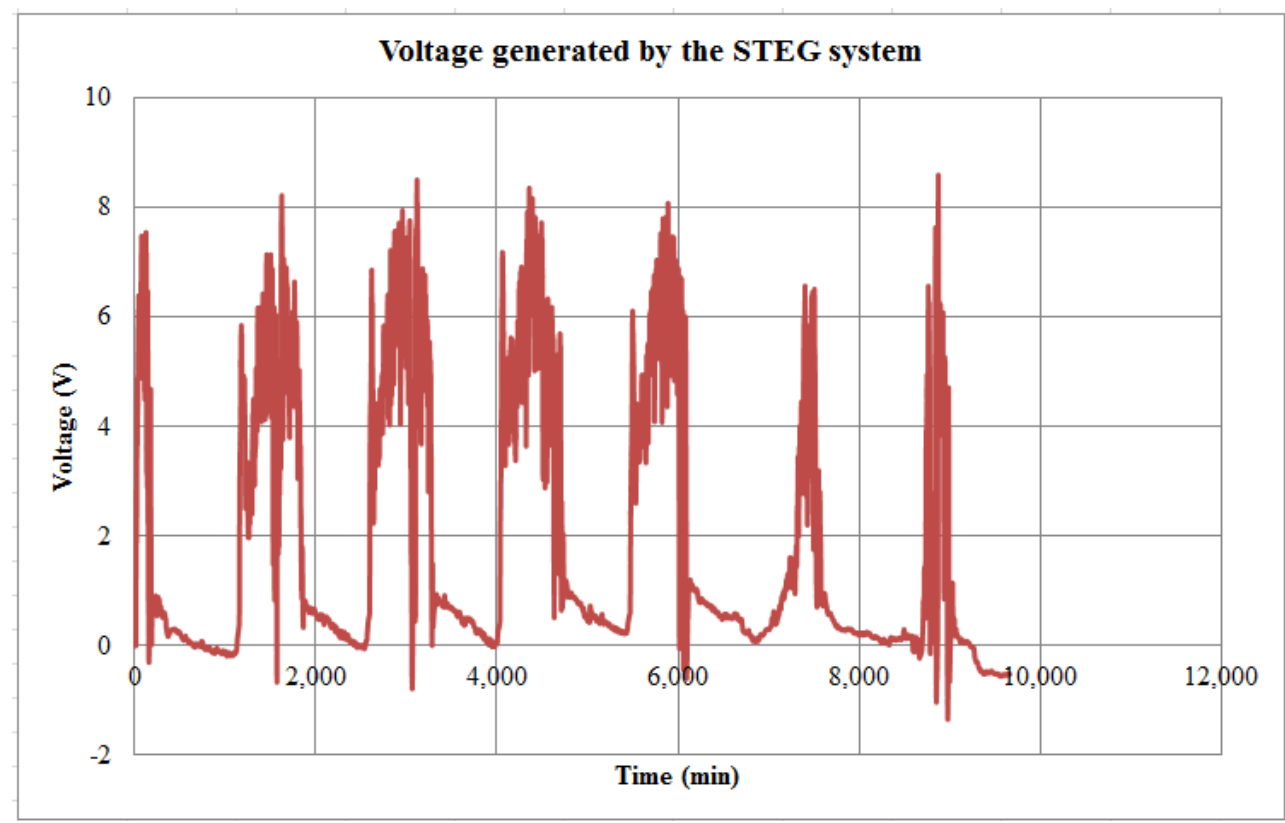

Fig. 8 Voltage waveform over seven (7) days.

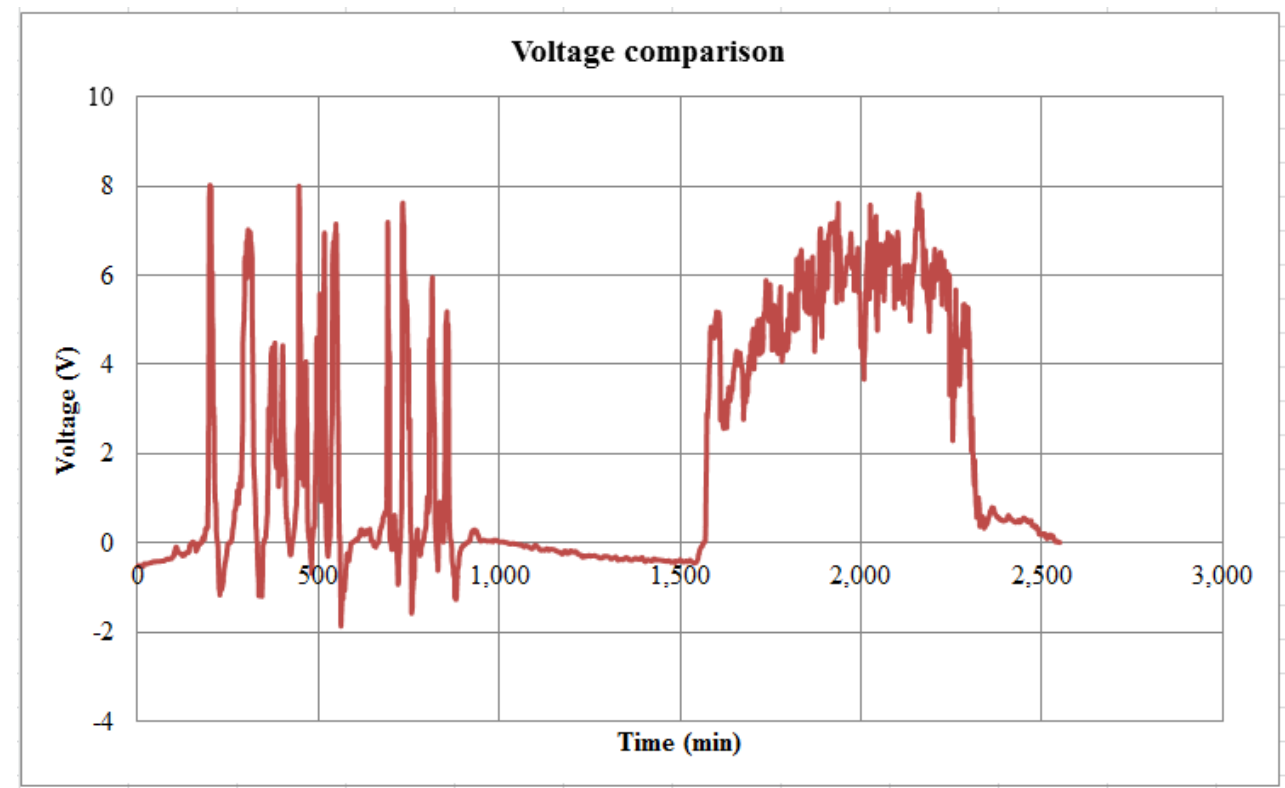

Fig. 9 Voltage comparison—typical cloudy day (left), and normal day (right).

to remote residential areas in developing regions. All the thermal capacitances and resistances of the various physical parts, which constitute the system, were computed based on the multipart geometries and properties of the device. An LTspice model for the entire system was then developed utilizing the thermal-to-electrical analogy schemes. The internal thermoelectric generators' parasitic inductances and capacitances variations with temperatures were captured in this model for accuracy purposes in the analogy. The local direct solar insulation was the only input to the system. Overall, the main objective for energy delivery to off-grid remote and developing regions was positively demonstrated and achieved. Simulated results were in good agreement with the experimental data recorded on site. Any error rate in the model can be explained by either one or both of the followings: (1) the internal parasitic components' 
variation and, (2) the non-homogeneity of the physical blocks that were assumed to be a pure aluminum heat exchanger during the computation of the thermal parameters.

This system in conjunction with battery energy storage can be utilized for all kinds of remote energy applications including domestic, telecommunications and bio-medicine.

\section{References}

[1] Crabtree, G. W., and Lewis, N. S. 2007. "Solar Energy Conversion." Phys. Today 60 (3): 37-42.

[2] Loh, P. C., Zhang, L., He, S., and Gao, F. 2010. "Compact Integrated Solar Energy Generation Systems." In Proceedings of the 2010 IEEE Energy Convers. Congr. Expo., 350-6.

[3] Moumouni, Y., Baghzouz, Y., and Boehm, R. F. 2014. "Power 'Smoothing' of a Commercial-Size Photovoltaic System by an Energy Storage System." In Proceedings of the International Conference on Harmonics and Quality of Power, ICHQP, 640-4.

[4] Nuwayhid, R. Y., Shihadeh, A., and Ghaddar, N. 2005. "Development and Testing of a Domestic Woodstove Thermoelectric Generator with Natural Convection Cooling." Energy Convers. Manag. 46 (9-10): 1631-43.

[5] Leonov, V., Torfs, T., Fiorini, P., and Van Hoof, C. 2007. "Thermoelectric Converters of Human Warmth for Self-Powered Wireless Sensor Nodes.” IEEE Sens. J. 7 (5): 650-7.

[6] Lofy, J., and Bell, L. E. 2002. "Thermoelectrics for Environmental Control in Automobiles." In Proceedings of the Twenty-First Int. Conf. Thermoelectr. 2002, Proc. ICT '02, 471-6.

[7] Chen, L., Cao, D., Huang, Y., and Peng, F. Z. 2008. "Modeling and Power Conditioning for Thermoelectric Generation." In Proceedings of the PESC Rec.-IEEE Annu. Power Electron. Spec. Conf., 1098-103.

[8] Ploteau, J. P., Glouannec, P., and Noel, H. 2007. "Conception of Thermoelectric Flux Meters for Infrared Radiation Measurements in Industrial Furnaces." Appl. Therm. Eng. 27 (2-3): 674-81.

[9] Matsubara, K. 2002. "Development of a High Efficient Thermoelectric Stack for a Waste Exhaust Heat Recovery of Vehicles." In Proceedings of the Twenty-First Int. Conf. Thermoelectr. 2002, Proc. ICT '02, 418-23.

[10] Paradiso, J. A., and Starner, T. 2005. "Energy Scavenging for Mobile and Wireless Electronics." IEEE Pervasive Comput. 4 (1): 18-27.

[11] Riffat, S., and Ma, X. 2003. "Thermoelectrics: A Review of Present and Potential Applications." Appl. Therm. Eng. 23 (8): 913-35.

[12] Rowe, D. M. 1999. "Thermoelectrics, An Environmentally-Friendly Electrical Power." Renew. Energy 16 (1-4): 1251-6.

[13] Rowe, D. M. 2012. "Thermoelectric Harvesting of Low Temperature Natural/Waste Heat." AIP Conf. Proc. 485 (June): 485-92.

[14] Zheng, X. F., Liu, C. X., Yan, Y. Y., and Wang, Q. 2014. "A Review of Thermoelectrics Research-Recent Developments and Potentials for Sustainable and Renewable Energy Applications." Renew. Sustain. Energy Rev. 32 (April): 486-503.

[15] Rinalde, G. F., Juanicó, L. E., Taglialavore, E., Gortari, S., and Molina, M. G. 2010. "Development of Thermoelectric Generators for Electrification of Isolated Rural Homes." Int. J. Hydrogen Energy 35 (11): 5818-22.

[16] Chen, M., Rosendahl, L. A., Bach, I., Condra, T., and Pedersen, J. K. 2006. "Transient Behavior Study of Thermoelectric Generator through SPICE Electro-Thermal Model." In Proceedings of the 25th International Conference on Thermoelectrics, ICT'06, 214-9.

[17] Cernaianu, M., and Cernaianu, A. 2012. "Thermo Electrical Generator Improved Model." Int. Conf. Power and Energy Systems-ICPES 13 (4): 343-8.

[18] Lineykin, S., and Ben-Yaakov, S. 2007. "Modeling and Analysis of Thermoelectric Modules." IEEE Trans. Ind. Appl. 43 (2): 505-12.

[19] Mirocha, A., and Dziurdzia, P. 2008. "Improved Electrothermal Model of the Thermoelectric Generator Implemented in SPICE." In Proceedings of the International Conference on Signals and Electronic Systems, 2008. ICSES '08, 317-20.

[20] Cernaianu, M. 2012. "Thermoelectrical Energy Harvesting System: Modelling, Simulation and Implementation." In Proceedings of the 2012 10th International Symposium on Electronics and Telecommunications (ISETC), 2-5.

[21] Gontean, A., and Cernaianu, M. O. 2013. "High-Accuracy Thermoelectrical Module Model for Energy-Harvesting Systems." IET Circuits, Devices Syst. 7 (3): 114-23.

[22] Gontean, A., and Cernaianu, M. O. 2013. "Parasitic Elements Modelling in Thermoelectric Modules." IET Circuits, Devices Syst. 7 (4): 177-84.

[23] Kraemer, D., Poudel, B., Feng, H. P., Caylor, J. C., Yu, B., Yan, X., Ma, Y., Wang, X., Wang, D., Muto, A., McEnaney, K., Chiesa, M., Ren, Z., and Chen, G. 2011. "High-Performance Flat-Panel Solar Thermoelectric Generators with High Thermal Concentration." Nat. Mater. 10 (7): 532-8. 
[24] Lineykin, S., and Ben-yaakov, S. 2005. "Modeling and Analysis of Thermoelectric Modules." In Proceedings of the IEEE Trans. Ind. Electron., 2019-23.

[25] Dziurdzia, P. 2011. "Modeling and Simulation of Thermoelectric Energy Harvesting Processes." In Sustainable Energy Harvesting Technologies-Past, Present and Future, edited by Yen, K. T. Polan: AGH University of Science and Technology in Cracow.

[26] Chavez, J., and Ortega, J. 2000. "SPICE Model of Thermoelectric Elements Including Thermal Effects." In Proceedings of the 17th IEEE Instrumentation and Measurement Technology Conference, IMTC 2000, 1019-23.

[27] Moumouni, Y. 2014. "A System Dynamics Model for Energy Planning in Niger.” Int. J. Energy Power Eng. 3
(6): 308 .

[28] Mastbergen, D., and Willson, B. 2005. "Generating Light from Stoves Using a Thermoelectric Generator." ETHOS Int. Stove Res. Conf., 15-27.

[29] Moumouni, Y., and Baker, R. J. 2015. "Concise Thermal to Electrical Parameters Extraction of Thermoelectric Generator for Spice Modeling." In Proceedings of the IEEE 58th Int. Midwest Symp., 9-12.

[30] Traeger, R. K. 1967. "Physical Properties of Rigid Polyurethane Foams.” J. Cell. Plast. 3 (9): 405-18.

[31] Widya, T., and Macosko, C. 2005. "Nanoclay Modified Rigid Polyurethane Foam." J. Macromol. Sci. Part B Phys. 44 (6): 897-908.

[32] Alaoui, C. 2011. "Peltier Thermoelectric Modules Modeling and Evaluation.” Int. J. Eng. 5 (1): 114-21. 